\title{
Triangular Fixation to Prevent Proximal Screw Pullout in Adult Spinal Deformity Surgery: A Technical Note
}

\section{Masato Tanaka ( $\square$ tanaka0896@gmail.com )}

Okayama Rosai Byoin https://orcid.org/0000-0001-6685-7451

\section{Rahul Mehta}

Okayama Rosai Hospital: Okayama Rosai Byoin

\section{Taro Yamauchi}

Okayama Rosai Hospital: Okayama Rosai Byoin

\section{Shinya Arataki}

Okayama Rosai Hospital: Okayama Rosai Byoin

\section{Koji Uotani}

Okayama Rosai Hospital: Okayama Rosai Byoin

\section{Yoshihiro Fujiwara}

Okayama Rosai Hospital: Okayama Rosai Byoin

\section{Kensuke Shinohara}

National Hospital

Kentaro Yamane

National Hospital

\section{Research Article}

Keywords: transdiscal screw, proximal junctional kyphosis, adult spinal deformity, pullout strength, C-arm free

Posted Date: October 27th, 2021

DOl: https://doi.org/10.21203/rs.3.rs-968617/v1

License: (c) (i) This work is licensed under a Creative Commons Attribution 4.0 International License. Read Full License

Version of Record: A version of this preprint was published at Interdisciplinary Neurosurgery on February 1st, 2022. See the published version at https://doi.org/10.1016/j.inat.2022.101514. 


\section{Abstract \\ Background}

Adult spinal deformity (ASD) is caused by spinal malalignment and results in severe low back pain, neurological dysfunction, and severe deformity. Proximal screw back-out represents a difficult problem in minimally invasive ASD surgery. We describe a novel technique to prevent screw pullout in ASD.

\section{Methods}

A 71-year-old woman was referred to our hospital with severe low back pain and gait difficulty. Her daily life had been affected by severe lower back pain for more than 6 months. Standing radiograms indicated severe kyphoscoliosis. Two-stage minimally invasive corrective T10-to-pelvis fixation was performed.

\section{Results}

The first surgery was an L1-S1 C-arm-free oblique lumbar interbody fusion, with an operation time of $3 \mathrm{~h}$ $57 \mathrm{~min}$ and an estimated blood loss of $240 \mathrm{~mL}$. After 1 week, the second percutaneous pedicle screw (PPS) fixation was performed and proximal screws were inserted under a transdiscal approach (T11) and with a lower angulation trajectory ( $\mathrm{T} 10)$ to enhance pullout strength. For this second surgery, operation time was $3 \mathrm{~h} 33 \mathrm{~min}$, and estimated blood loss was $320 \mathrm{~mL}$. No postoperative complications or neurological compromise was reported. In terms of clinical outcomes, Oswestry Disability Index improved from $56-24 \%$, and visual analog scale score for lower back pain improved from $62 \mathrm{~mm}$ to $24 \mathrm{~mm}$ at the 1-year follow-up.

\section{Conclusions}

Minimally invasive circumferential surgery with triangular fixation is effective for preventing proximal screw back-out and surgical invasiveness. With this new technique, surgeons and operating room staff can avoid the risk of adverse events due to intraoperative radiation exposure.

\section{Background}

Adult spinal deformity (ASD) affects a large number of patients ( $8.9 \%$ of individuals $>40$ years old and $68 \%$ of those $>60$ years old and is caused by spinal malalignment, resulting in severe low back pain, neurological dysfunction, and severe deformity of the body [1,2]. Surgical treatment offers improved patient-reported outcomes compared to conservative treatment [3]. However, the complication rate of ASD surgery is reportedly very high $(10-45 \%)[4,5]$. Circumferential minimally invasive surgery (cMIS) to reduce the morbidities and perioperative complications of ASD has been receiving increasing attention [6]. 
Proximal junctional kyphosis (PJK) occurs at the rostral junction between the fixed instrumented spinal segment and overlying mobile vertebral levels after ASD surgery. PJK is defined by a proximal junctional sagittal Cobb angle $\geq 10^{\circ}$, and also $\geq 10^{\circ}$ more than the preoperative measurement. If this condition requires revision surgery, it is referred to as proximal junctional failure (PJF) [7]. PJF is one of the most common complications of ASD surgery [8]. To prevent PJK and pullout of proximal screws, options such as taping [9], bone cement [10], administration of parathyroid hormone [11], and semi-rigid junctional fixation [12] have been proposed. However, these options are difficult to adapt to cMIS techniques. We present herein a novel technique to prevent screw pullout in adult spinal deformity surgery.

\section{Methods}

\section{Case presentation}

\section{Patient history}

A 71-year-old woman was referred to our orthopedic department with severe low back pain and gait difficulty. Her daily life had been affected by low back pain for more than 6 months.

\section{Physical examination}

The patient could not walk or stand unaided. On examination, the patient could walk for only $100 \mathrm{~m}$ due to left leg pain and low back pain (Figure 1A, B). No hyperreflexia of the legs was detected, and abdominal reflexes were normal, but the patient experienced severe pain in the left leg with limited range of spine motion.

\section{Preoperative imaging}

Radiograms at initial visit demonstrated severe degenerative lumbar scoliosis. Preoperative spinal radiograms indicated coronal sagittal malalignment: Cobb angle, $52^{\circ}$ (L2-5); coronal trunk shift, $40 \mathrm{~mm}$; sagittal vertical axis (SVA), $27 \mathrm{~mm}$; pelvic tilt (PT), 36\% (Figure 1C, D). Preoperative computed tomography (CT) indicated L3 lateral slip, osteoarthritis and disc air vacuum phenomenon (Figure 2). Preoperative magnetic resonance imaging revealed severe disc degeneration from L1 to L5 and mild stenosis at both the L3-4 and L4-5 level (Figure 3). She had severe osteoporosis (bone mineral density, $0.642 \mathrm{~g} / \mathrm{cm}^{2} ; \mathrm{T}$ score, -2.0

\section{Results}

\section{Surgery and postoperative imaging}

The patient underwent two-stage C-arm-free cMIS. The first surgery comprised L1-S1 C-arm-free oblique lumbar interbody fusion (OLIF), with an operation time of $3 \mathrm{~h} 57 \mathrm{~min}$ and an estimated blood loss of 240 $\mathrm{mL}$. After 1 week, the second PPS_fixation was performed and proximal screws $(\mathrm{T} 10, \mathrm{~T} 11)$ were inserted 
with a transdiscal approach (T11) and with lower angulation trajectory (T10) to enhance pullout strength (Figure 4). For this second stage, operative time was $3 \mathrm{~h} 33 \mathrm{~min}$ and estimated blood loss was $320 \mathrm{~mL}$. No postoperative complications or neurological compromise was reported.

\section{Follow-up results and imaging}

Follow-up radiography showed no PJK or screw loosening (Figure 5). In terms of clinical outcomes, Oswestry Disability Index improved from $56 \%$ to $24 \%$ and visual analog scale score for neck pain improved from $62 \mathrm{~mm}$ to $24 \mathrm{~mm}$ by the 1-year follow-up.

\section{Operation procedure}

\section{First surgery (L1-S1 OLIF)}

The patient was placed in the right lateral decubitus position on an adjustable hinged carbon operating table (OSI Axis Jackson table; Mizuho, Union City, CA, USA) to perform CT using an 0-arm. An axillary roll was placed to protect the neurovascular structures in the axilla. The patient was secured to the Axis Jackson table with tape, and the table was adjusted to approximately $15^{\circ}$ convex. The percutaneous reference frame was attached through the sacroiliac joint. The 0-arm was then positioned, and 3dimensional (3D) reconstructed images were obtained and transmitted to the Stealth station navigation system Spine $7^{\circledR}$ (Medtronic Sofamor Danek; Minneapolis, MN, USA). After verifying every navigated spinal instrument, the best entry point for each disc was marked by the navigated pinpoint probe. Typically, three oblique skin incisions of approximately $4 \mathrm{~cm}$ each are necessary for this technique.

The subcutaneous fat layers were dissected until the abdominal musculature was reached. The external, internal, and transverse abdominal muscles were divided parallel with the alignment of the muscle fibers to avoid cutting the muscle fibers. Both index fingers were inserted inside the retroperitoneal space, and were used to follow the internal abdominal wall posteriorly down to the psoas muscle, which can be visualized. The navigated first direct lateral dilator rested on the anterior border of the psoas muscle at the L5-S1 disc level. Use of a hand-held retractor with illumination placed between the peritoneal contents and the probe was used to minimize the risk of injury to the ureter and vascular structures anteriorly. The retractor assembly was attached to the flexible arm and stability pins were inserted to fix the retractor. Discectomy was performed using a bayoneted knife, Kerrison rongeurs, pituitary forceps, a navigated Cobb elevatorium, a navigated shaver (Figure 5) and navigated curved curettes (Figure 6A, B). After trialing (Figure 6C, D), a mixture of iliac bone and demineralized bone material was inserted into the cage hole. A mallet was then used to gently insert the OLIF cage (Clydesdale PTC ${ }^{\circledR}$, OLIF51 Sovereign ${ }^{\mathrm{TM}}$ Spinal 173 System; Medtronic Sofamor Danek) while monitoring placement (Figure 8).

\section{Second surgery -Percutaneous pedicle screw (PPS) fixation}

The patient was placed in the prone position on the Axis Jackson table. The reference frame was attached around the T11 spinous process and 3D images were obtained from T10 to L3. After every 
navigated instrument was verified, PPS was inserted by navigation (Figure 9). The length and diameter of pedicle screw were also measured by navigation. After T10-L3 screws were inserted, the reference frame was reattached to $L 3$, and another 3D image was obtained from $L 4$ to the pelvis. Sacral-alar-iliac (SAI) screws are recommended to enhance the pelvic anchors. The proximal screws (T10, T11) are inserted with a transdiscal approach (T11) (Figure 10) and with lower angulation trajectory (T10) (Figure 11) to enhance pullout strength. This technique results in triangular fixation of the upper instrumented vertebra (UIV) to prevent screw pull-out (Figure 12).

Anteroposterior and lateral radiograms should be obtained to ensure correct placement of pedicle screws and SAI screws. Rods were bent in an appropriate contour and inserted percutaneously. The Axis Jackson table was bent by more than $20^{\circ}$ to create good lumbar lordosis. The set screws were gradually tightened to create a greater amount of lumbar lordosis.

\section{Discussion}

For ASD, surgery shows better results than conservative treatment, but is associated with many complications [3]. PJK is one such complication. Risk factors for PJK include older age, greater preoperative sagittal imbalance, large correction of sagittal deformity, anteroposterior spinal fusion, fusion to the sacrum, low bone density, and a high body mass index [14]. PJFs involve more serious clinical problems after long segment fusions in patients with ASD and require surgical treatment. PJF is a progressive form of the PJK spectrum, including vertebral fracture of UIV or UIV+1, subluxation between UIV and UIV+1, failure of fixation, and neurological deficits [15]. The prevalence of PJF ranges between $1.4 \%$ and $25 \%$, with a mean time of 11.4 weeks to 6 months after primary surgery $[15,16]$. The structural failure that occurs with PJF can present as vertebral body fracture, implant pull-out or breakage, and/or disruption of the posterior osteo-ligamentous complex $[16,17]$.

Several multifactor-based strategies are available to reduce the incidences of PJK and PJF, such as preserving the interspinous and supraspinous ligaments and facet joint capsules at the UIV. With the advent of percutaneous pedicle screw fixation by applying minimally invasive surgery (MIS) principles, the soft tissue injuries and perioperative complications associated with open surgery can be minimized [18]. Osteoporosis is another factor responsible for increased hardware failure, such as screw cutout, screw pull out and higher incidences of PJK/PJF, thus increasing the risk of ASD patients needing revision surgeries [19]. Various techniques have been advised to reduce the chances of screw pull out. Expandable screws offer $60 \%$ higher pullout strength than traditional pedicle screws, but their availability and cost remain as important constraints. Moreover, these screws are mainly available for open fixations [20]. Bicortical screws are longer and $26 \%$ stronger than traditional pedicle screws, but this technique carries a major risk of injury to the great vessels lying anteriorly [21]. Screws with cement augmentation show an $86 \%$ improvement in pullout strength. This technique is very commonly used, but at the same time carries risks of cement leakage like pulmonary embolism, radicular symptoms and neurological injury [22]. Techniques that can be used in conjunction with MIS without increasing complication rates or adding to the financial burdens remain scant. 
We have suggested an innovative surgical technique to reduce the chances of screw pull-out and PJK/PJF, in addition to maintaining the advantages of MIS procedures. We suggest inserting a transdiscal screw at the UIV-1 level. Abdu et al. in 1994 offered the first description of using transdiscal screw fixation for the management of spondylolisthesis. A trans-discal screw offers better pullout strength than a straight forward screw, at 1.6- to 1.8-times stronger than a traditional pedicle screw [23]. Inserting a trans-discal screw is avoided during UIV to prevent injury to the proximal junctional disc. Conversely, the UIV screw is placed directed cranio-caudally to get make maximum use of the length of the screw and obtain a triangular construct at the proximal end of the construct.

A triangular construct (Figure 12) offers superior fixation strength, since it depends on the mass of bone between the hardware rather than screw purchase alone [24]. Also, in osteoporotic bone, the insertion angle minimally affects the pull-out force. Insertion angle also has no significant effect on insertion torque and is based on the material properties of the bone and the length of screw engagement [25]. Longer screws thus offer better purchase. Another advantage of placing the UIV screw cranio-caudally is that significantly more bone is available cranial to the screw surface to resist the screw cut-out.

Considering all these advantages to this technique with no added complications or financial burden and its applicability to MIS, we propose that adoption of similar techniques may significantly reduce the rates of complications related to bone-implant interface and thus the incidence of PJF.

\section{Conclusion}

Proximal triangular fixation is a useful technique to prevent screw pullout for adult spinal deformity surgery. This technique is available for cMIS such as percutaneous pedicle screw fixation.

\section{Abbreviations}

ASD: adult spinal deformity

cMIS: circumferential minimally invasive surgery

CT: computed tomography

LL: lumbar lordosis

MIS: minimally invasive surgery

MRI: magnetic resonance imaging

OLIF: oblique lumbar interbody fusion

PI: pelvic incidence

PJF: proximal junctional failure 
PJK: proximal junctional kyphosis (PJK)

PPS: percutaneous pedicle screws

PT: pelvic tilt

SAl: sacroalar iliac

SVA: sagittal vertical axis

UIV: upper instrumented vertebra

3D: 3-dimensional

\section{Declarations}

\section{Ethics approval and consent to participate}

The institutional ethics committee provided approval for this study (No.306). Necessary consents were obtained from the patient.

\section{Consent for publication}

We, the undersigned, give our consent for the publication of identifiable details, which can include figures, tables, case history and details within the text to be published in the Journal of Orthopaedic Surgery and Research.

\section{Availability of data and materials}

This study does not contain any third material.

\section{Competing interests}

The authors declare that they have no competing interests

\section{Funding}

This research did not receive any specific grant from funding agencies in the public, commercial, or notfor-profit sectors.

\section{Authors' contributions}

MT performed most of the practical work, analyzed the data and prepared the manuscript. RM participated in the planning of the preparation of the manuscript. SA and YF participated in the data gathering. KS and KY supervised the study planning, data analysis and preparation of the manuscript. All authors read and approved the final manuscript. 
Acknowledgements

This study was supported by Okayama Spine Group.

Authors' information

Department of Orthopaedic Surgery, Okayama Rosai Hospital, Okayama 702-8055, Japan

Department of Orthopaedic Surgery, National Okayama Hospital, Okayama 701-1192, Japan

\section{References}

1. Kebaish KM, Neubauer PR, Voros GD, Khoshnevisan MA, Skolasky RL. Scoliosis in adults aged forty years and older: prevalence and relationship to age, race, and gender. Spine 2011, 36, 731-736.

2. Schwab F, Dubey A, Gamez L, et al. Adult scoliosis: prevalence, SF-36, and nutritional parameters in an elderly volunteer population. Spine $2005,30,1082-1085$.

3. Cho SK, Shin JI, Kim YJ. Proximal junctional kyphosis following adult spinal deformity surgery. Eur Spine J. $2014,12,2726-2736$.

4. Sciubba DM, Yurter A, Smith JS, Kelly MP, Scheer JK, Goodwin CR, Lafage V, Hart RA, Bess S, Kebaish $\mathrm{K}$, Schwab F, Shaffrey $\mathrm{Cl}$, Ames $\mathrm{CP}$. A comprehensive review of complication rates after surgery for adult deformity: a reference for informed consent. Spine Deform 2015, 6, 575e.

5. Nicholls FH, Bae J, Theologis AA, Eksi MS, Ames CP, Berven SH, Burch S, Tay BK, Deviren V. Factors associated with the development of and revision for proximal junctional kyphosis in $\mathbf{4 4 0}$ consecutive adult spinal deformity patients. Spine $2017,42,1693 \mathrm{e} 8$.

6. Tanaka M, Fujiwara Y, Uotani K, Maste P, Yamauchi T. C-Arm-Free Circumferential Minimally Invasive Surgery for Adult Spinal Deformity: Technical Note. World Neurosurg. 2020, 143, 235-246.

7. Hart RA, McCarthy I, Ames CP, Shaffrey Cl, Hamilton DK, Hostin R. Proximal junctional kyphosis and proximal junctional failure. Neurosurg Clin N Am. 2013, 24, 213-218.

8. Eastlack RK, Srinivas R, Mundis GM, Nguyen S, Mummaneni PV, Okonkwo DO, Kanter AS, Anand N, Park P, Nunley P, Uribe JS, Akbarnia BA, Chou D, Deviren V; International Spine Study Group. Early and Late Reoperation Rates With Various MIS Techniques for Adult Spinal Deformity Correction. Global Spine J. 2019, 9, 41-47.

9. Rodriguez-Fontan F, Reeves BJ, Noshchenko A, Ou-Yang D, Kleck CJ, Cain C, Burger-Van der Walt E, Patel VV. Strap stabilization for proximal junctional kyphosis prevention in instrumented posterior spinal fusion. Eur Spine J. 2020, 29, 1287-1296.

10. Ghobrial GM, Eichberg DG, Kolcun JPG, Madhavan K, Lebwohl NH, Green BA, Gjolaj JP. Prophylactic vertebral cement augmentation at the uppermost instrumented vertebra and rostral adjacent vertebra for the prevention of proximal junctional kyphosis and failure following long-segment fusion for adult spinal deformity. Spine J. 2017, 17, 1499-1505. 
11. Karikari IO, Metz LN. Preventing Pseudoarthrosis and Proximal Junctional Kyphosis: How to Deal with the Osteoporotic Spine. Neurosurg Clin N Am. 2018, 29,365-374.

12. Viswanathan VK, Ganguly R, Minnema AJ, DeVries Watson NA, Grosland NM, Fredericks DC, Grossbach AJ, Viljoen SV, Farhadi HF. Biomechanical assessment of proximal junctional semi-rigid fixation in long-segment thoracolumbar constructs. J Neurosurg Spine. 2018, 30, 184-192.

13. Glattes RC, Bridwell KH, Lenke LG, Kim YJ, Rinella A, Edwards 2nd C. Proximal junctional kyphosis in adult spinal deformity following long instrumented posterior spinal fusion: incidence, outcomes, and risk factor analysis. Spine 2005, 30, $1643 \mathrm{e} 9$.

14. Maruo K, Ha Y, Inoue S, Samuel S, Okada E, Hu SS, Deviren V, Burch S, William S, Ames CP, Mummaneni PV, Chou D, Berven SH. Predictive factors for proximal junctional kyphosis in long fusions to the sacrum in adult spinal deformity. Spine 2013, 38, E1469e76.

15. Park SJ, Lee CS, Chung SS, Lee JY, Kang SS, Park SH: Different risk factors of proximal junctional kyphosis and proximal junctional failure following long instrumented fusion to the sacrum for adult spinal deformity: survivorship analysis of 160 patients. Neurosurgery 2017, 80, 279-286.

16. Yagi M, Rahm M, Gaines R, Maziad A, Ross T, Kim HJ, Kebaish K, Boachie-Adjei O; Complex Spine Study Group. Characterization and surgical outcomes of proximal junctional failure in surgically treated patients with adult spinal deformity. Spine. 2014, 39, E607-14.

17. Hostin R, McCarthy I, O’Brien M, Bess S, Line B, Boachie-Adjei O, et al: Incidence, mode, and location of acute proximal junctional failures after surgical treatment of adult spinal deformity. Spine 2013, 38, 1008-1015.

18. Bae J, Lee SH. Minimally Invasive Spinal Surgery for Adult Spinal Deformity. Neurospine. 2018, 1, 1824.

19. Gupta A., Cha T., Schwab J., Fogel H., Tobert D.G., Razi A.E., Paulino C., Hecht A.C., Bono C.M., Hershman S. Osteoporosis is underrecognized and undertreated in adult spinal deformity patients $\mathrm{J}$ Spine Surg 2021, 7, 1-7.

20. Wan S, Lei W, Wu Z, Liu D, Gao M, Fu S. Biomechanical and histological evaluation of an expandable pedicle screw in osteoporotic spine in sheep. Eur Spine J. 2010, 19, 2122-2129.

21. Santoni BG, Hynes RA, McGilvray KC, Rodriguez-Canessa G, Lyons AS, Henson MA, Womack WJ, Puttlitz CM. Cortical bone trajectory for lumbar pedicle screws. Spine J. 2009, 9, 366-373.

22. Paré PE, Chappuis JL, Rampersaud R, Agarwala AO, Perra JH, Erkan S, Wu C. Biomechanical evaluation of a novel fenestrated pedicle screw augmented with bone cement in osteoporotic spines. Spine. 2011, 36, E1210

23. Minamide A, Akamaru T, Yoon ST, Tamaki T, Rhee JM, Hutton WC. Transdiscal L5-S1 screws for the fixation of isthmic spondylolisthesis: a biomechanical evaluation. J Spinal Disord Tech. 2003, 16, 144-149.

24. Abdu W. A., Wilber R. G., Emery S. E. Pedicular transvertebral screw fixation of the lumbosacral spine in Spondylolisthesis. Spine 1994, 19, 710-715. 
25. Varghese V, Saravana Kumar G, Krishnan V. Effect of various factors on pull out strength of pedicle screw in normal and osteoporotic cancellous bone models. Med Eng Phys. 2017, 40, 28-38.

\section{Figures}
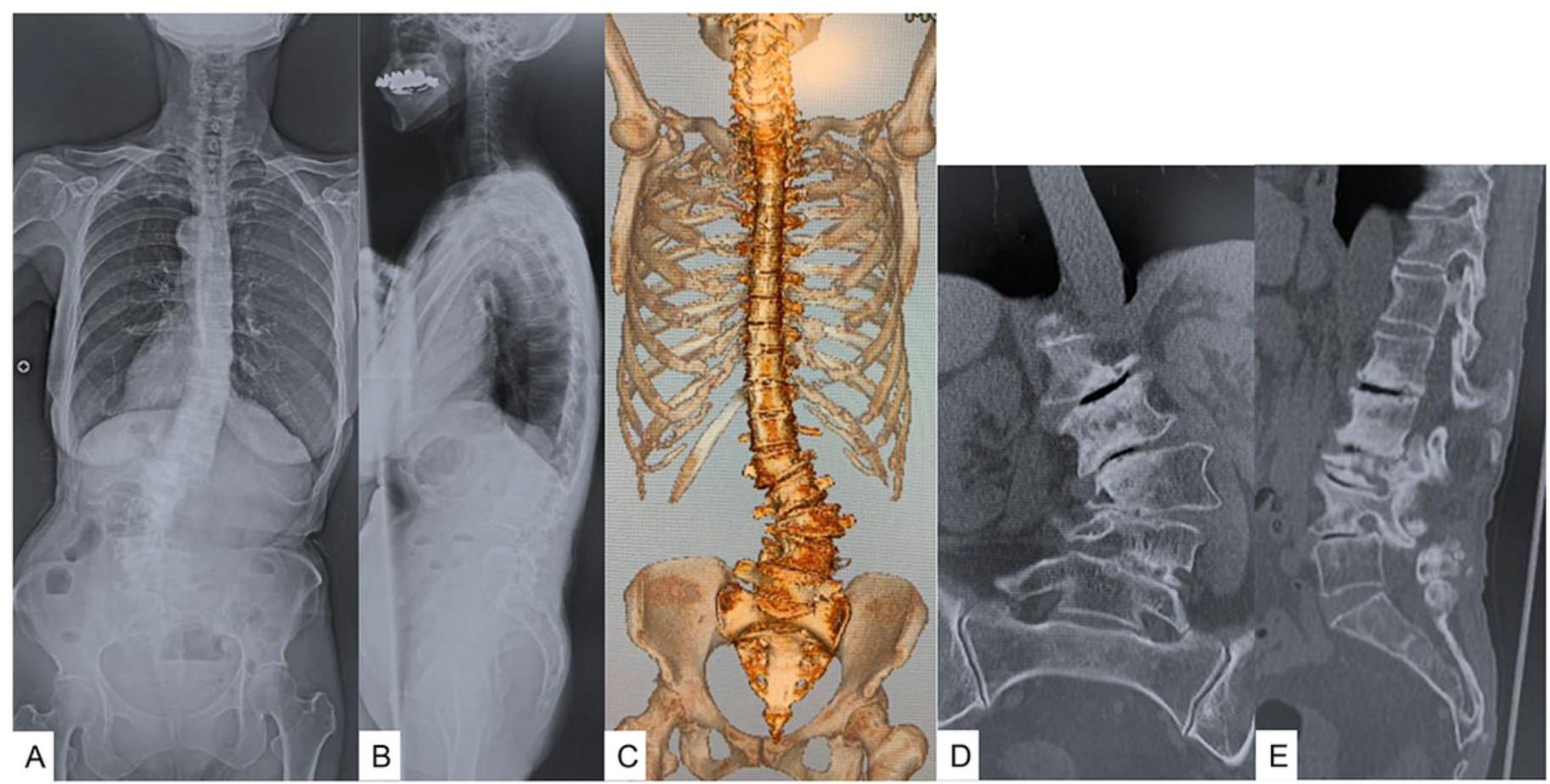

\section{Figure 1}

Preoperative figure and radiograms A: Posteroanterior view shows $52^{\circ}$ of scoliosis. B: Lateral radiogram shows severe sagittal malalignment; SVA of $27 \mathrm{~mm}, \mathrm{PT}$ of $57^{\circ}$, LL of $10^{\circ}$, and PI of $58^{\circ}$.C-D: CT 
Figure 2

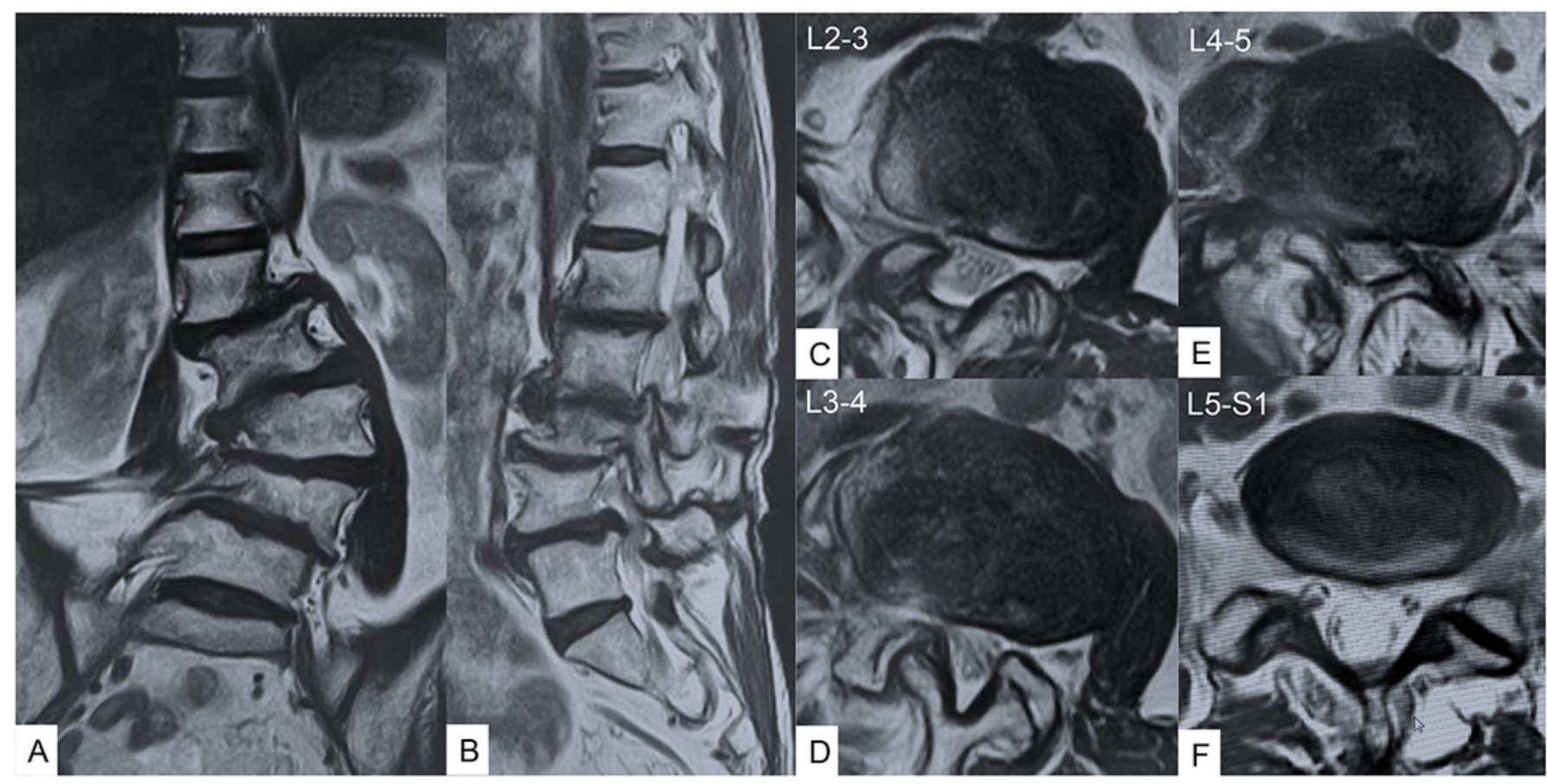

\section{Figure 2}

Preoperative magnetic resonance imaging. A: T2 weighted coronal image: severe disc degeneration was observed from the L1 to L5 disc space. B: T2 weighted sagittl image: C-F: T2 weighted axial images: the psoas muscles are atrophic and intermediate spinal canal stenosis is present at the L3-4 and L4-5 level. 


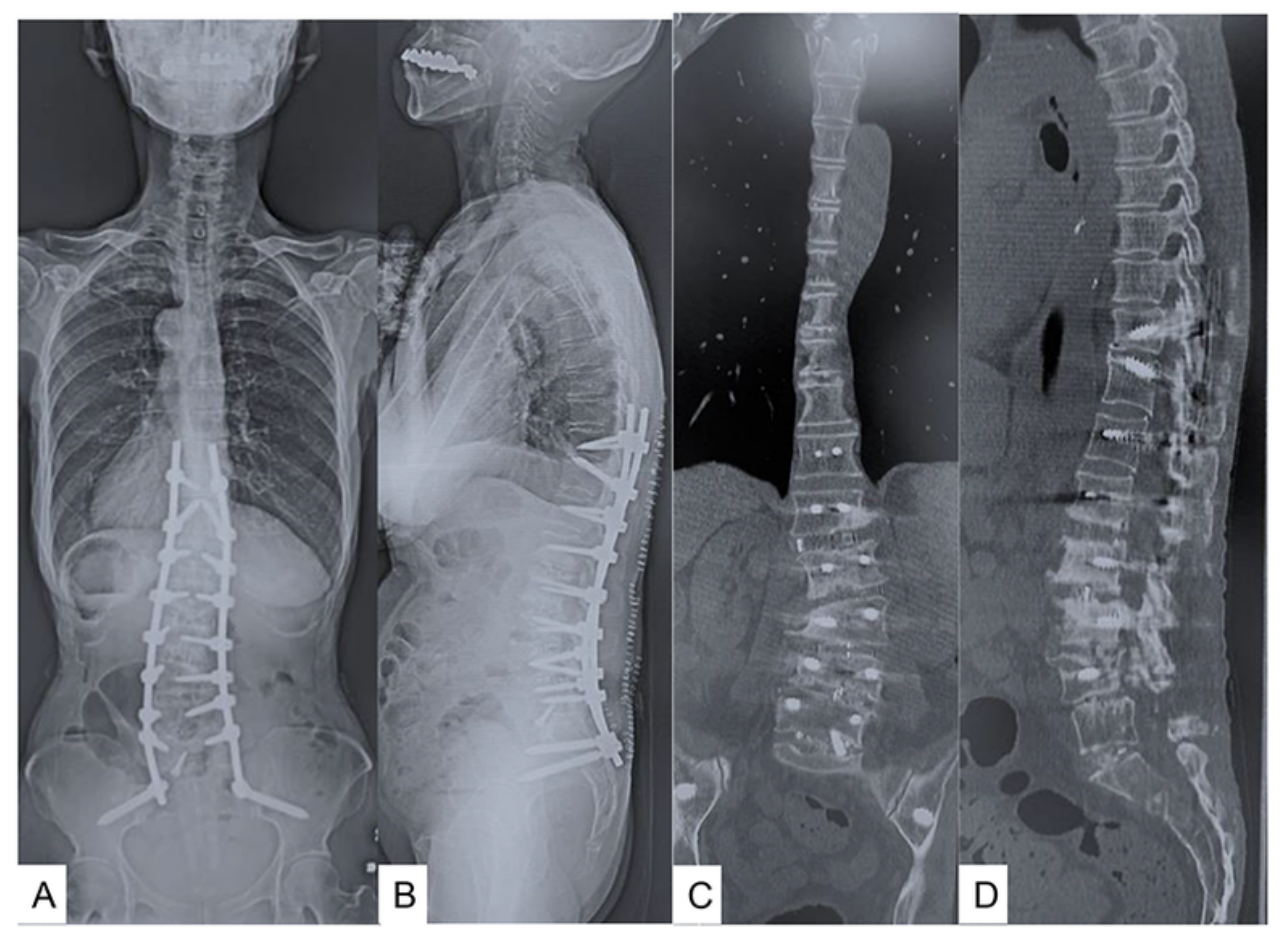

Figure 3

\section{Figure 3}

Postoperative figure and CT A: Posteroanterior view: Lumbar scoliosis was reduced from $57^{\circ}$ to $14^{\circ}$. B: Lateral radiogram shows good sagittal alignment; SVA $44 \mathrm{~mm}, \mathrm{PT} 19^{\circ}, \mathrm{LL} 56^{\circ}, \mathrm{PI} 57^{\circ}$. C: Coronal reconstruction CT: a good coronal alignment is obtained.D: Sagittal reconstruction CT: a good sagittal alignment is obtained. 
Figure 4

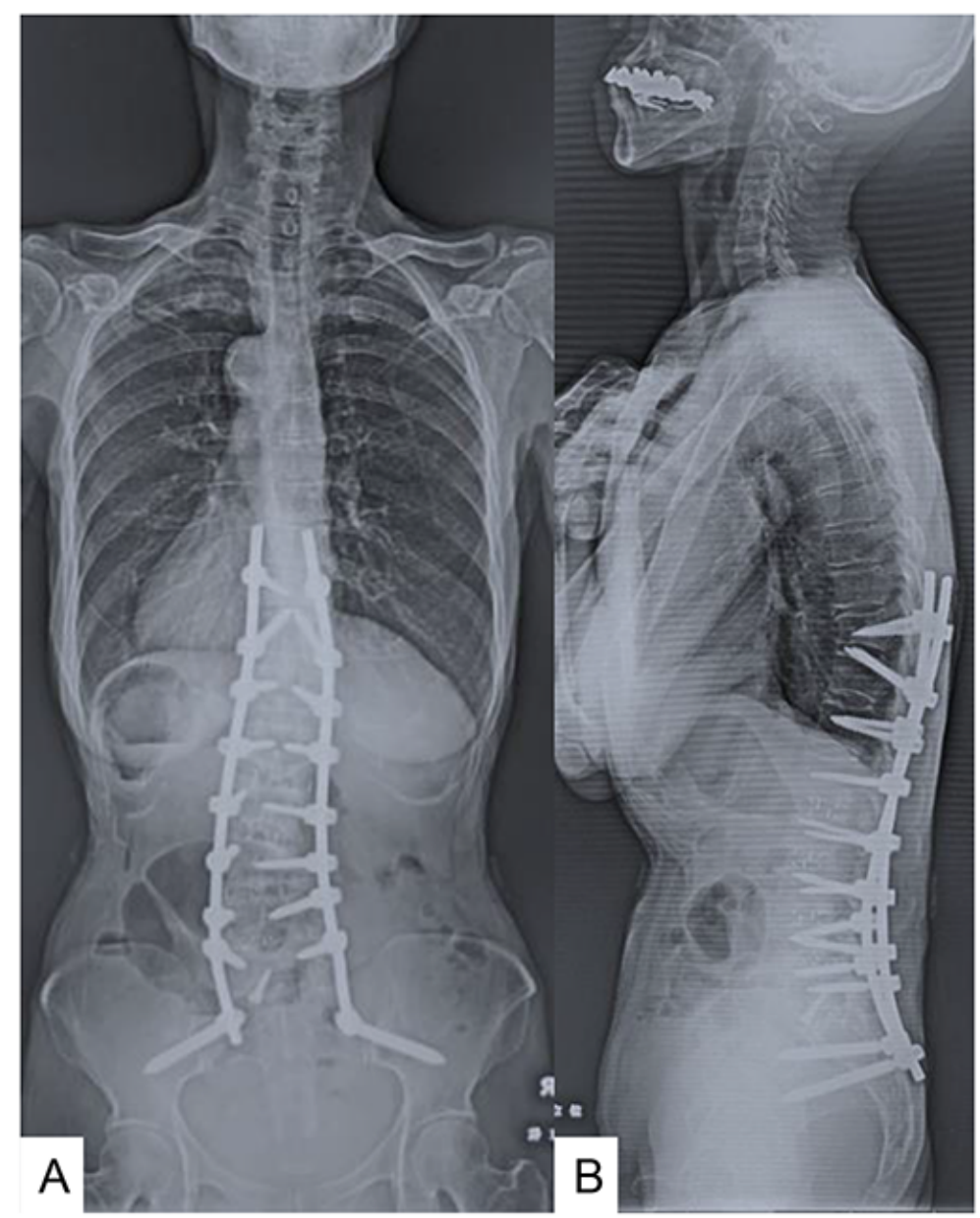

\section{Figure 4}

Final follow-up radiograms A; Posteroanterior radiogram, B; Lateral radiogram. Solid bony fusion was obtained. 
Figure 5

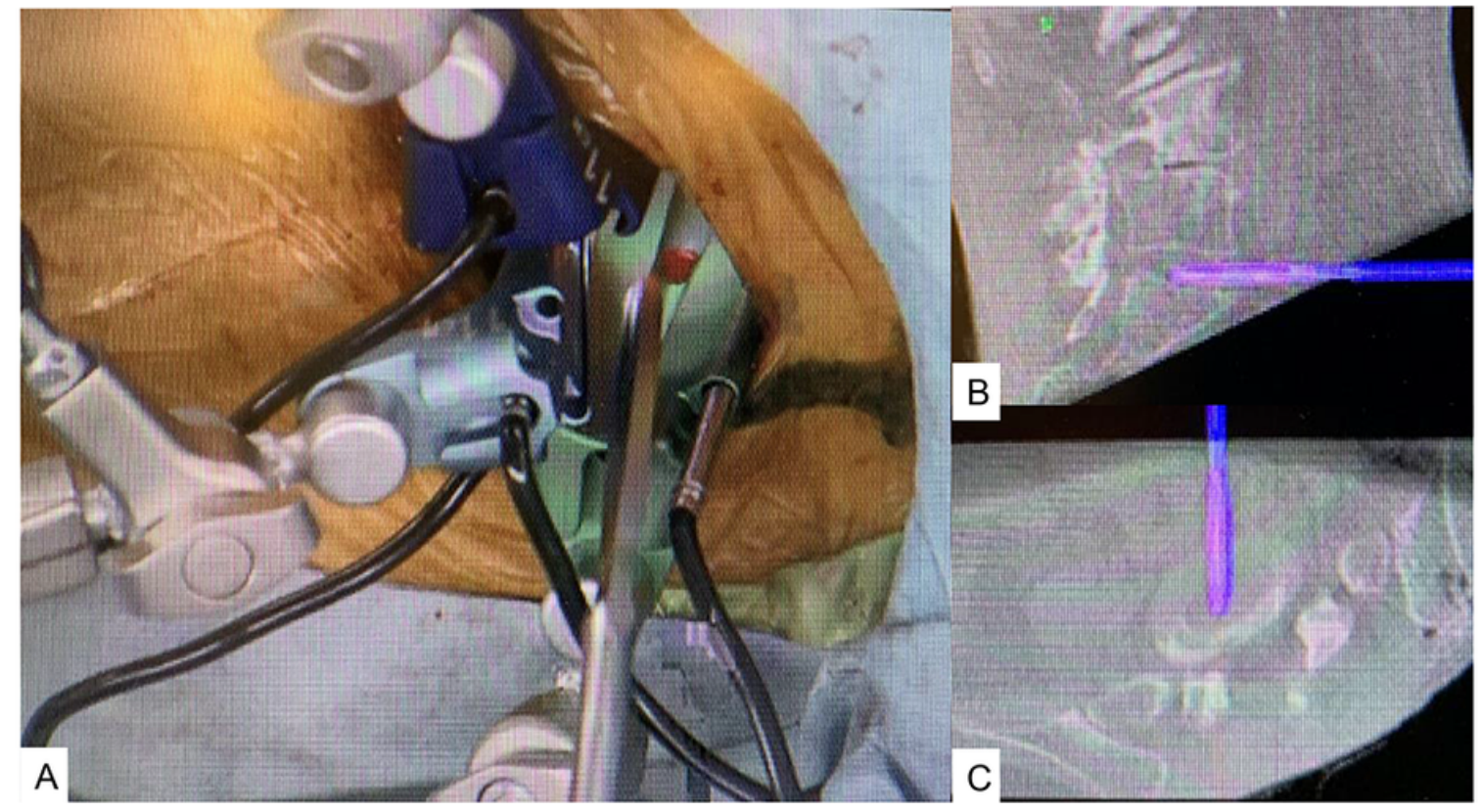

Figure 5

Nagigated shaver A; intraoperative image, B; Sagittal image, C; Axial image

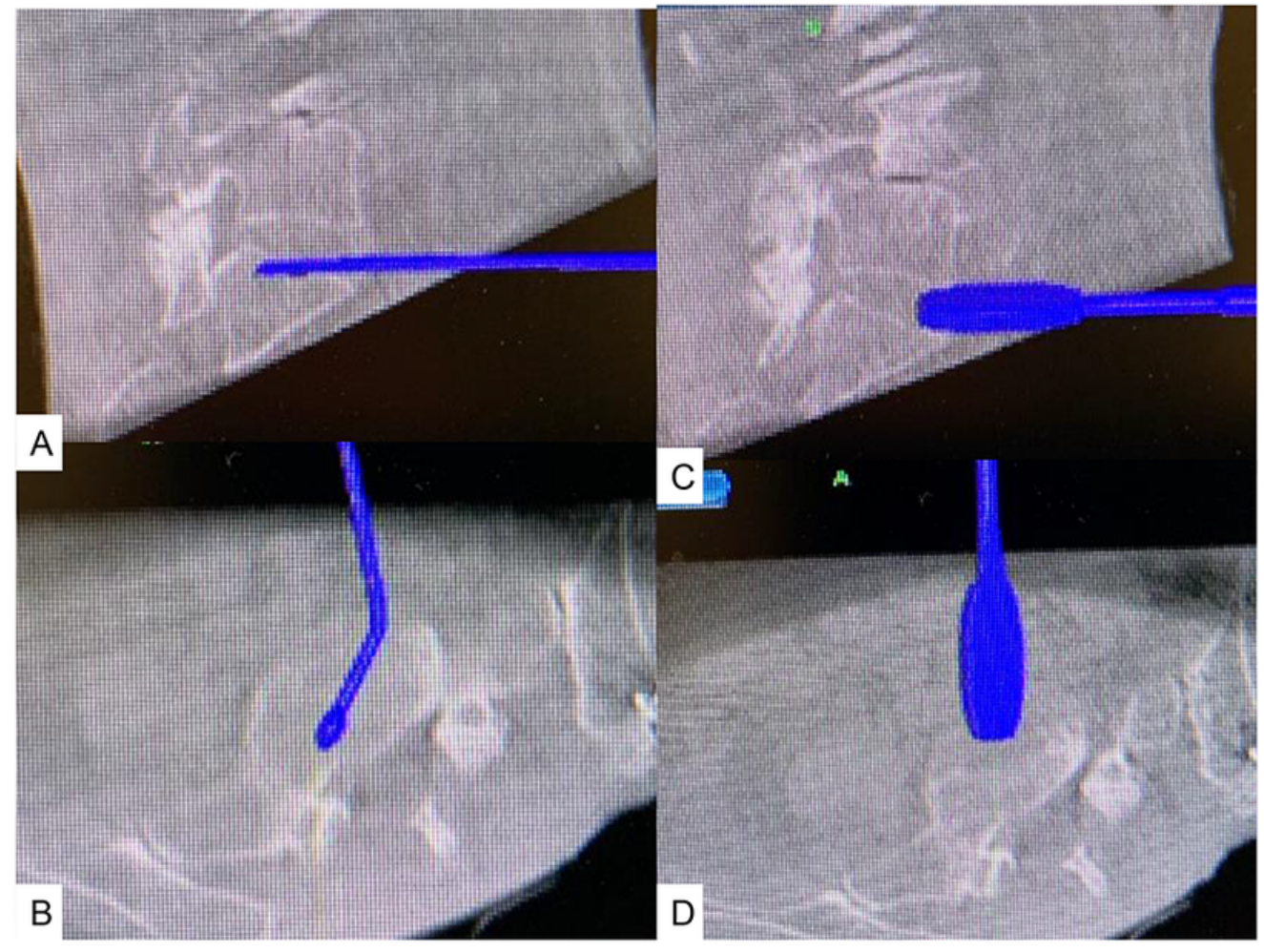

Figure 6 


\section{Figure 6}

Nagigated currette and traial A,C; Sagittal images of currette and trail, B,D: Axial images of currette and traial

Figure 7

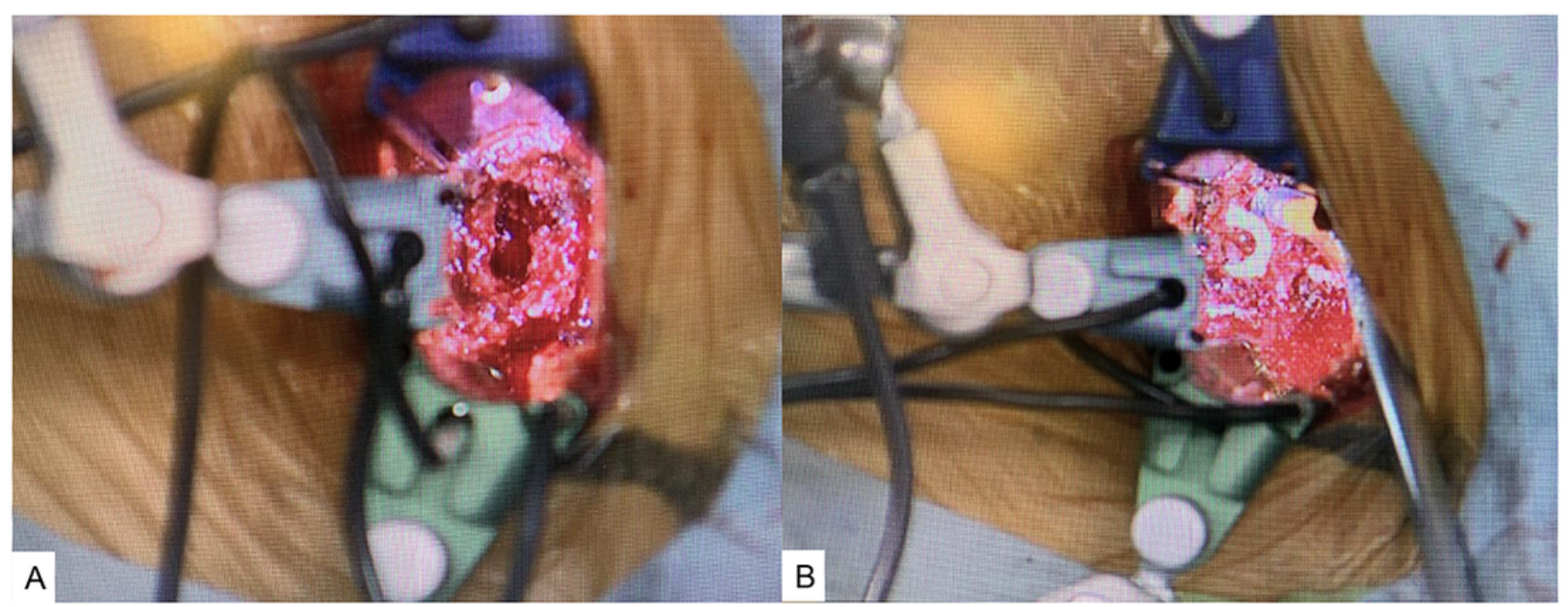

Figure 7

Cage insertion A; After disc preparation, B; After cage insertion 
Figure 8

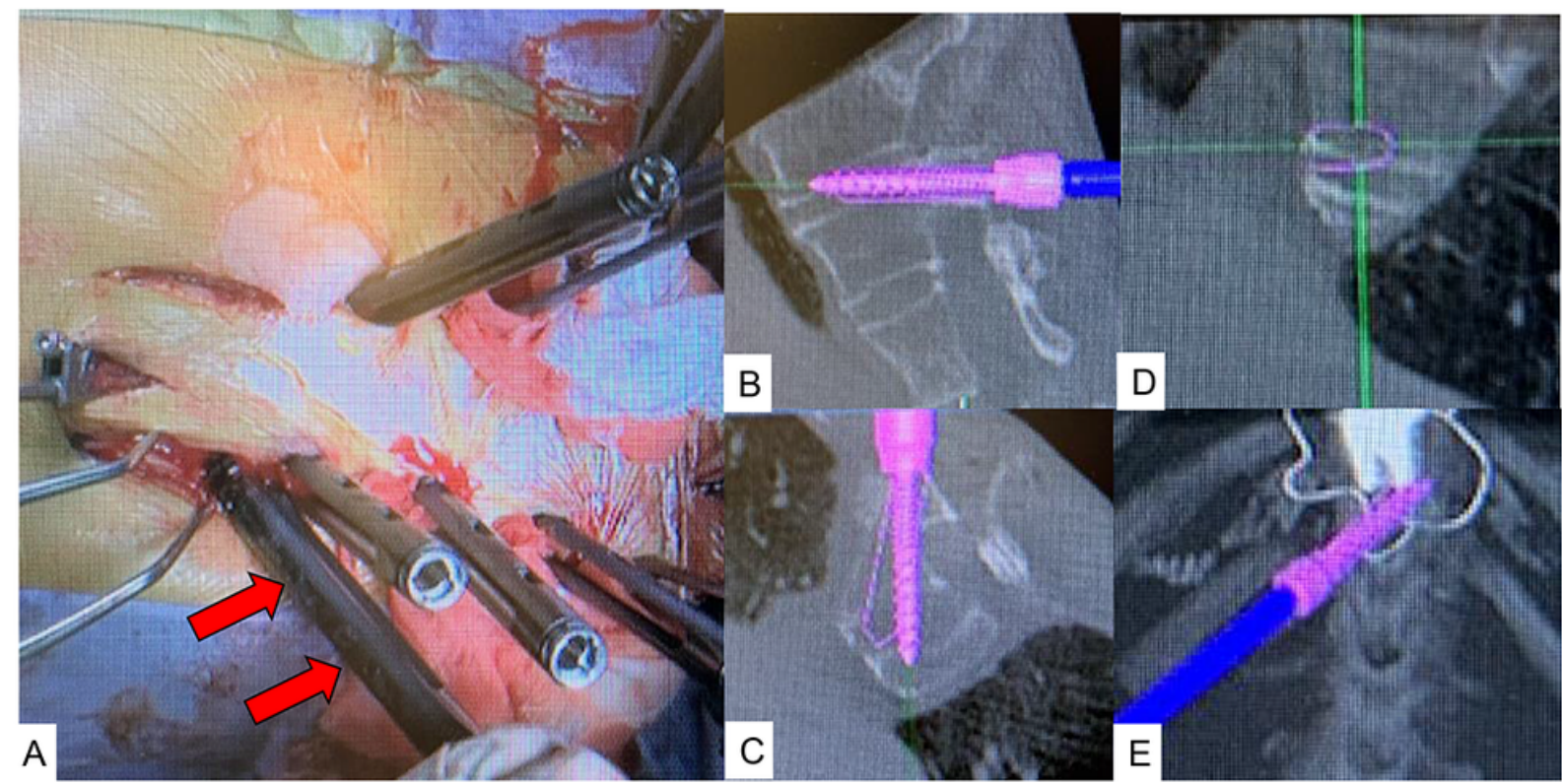

\section{Figure 8}

Transdiscal screw The pullout strength of transdiscal screw is stronger than that of normal screw

Figure 9

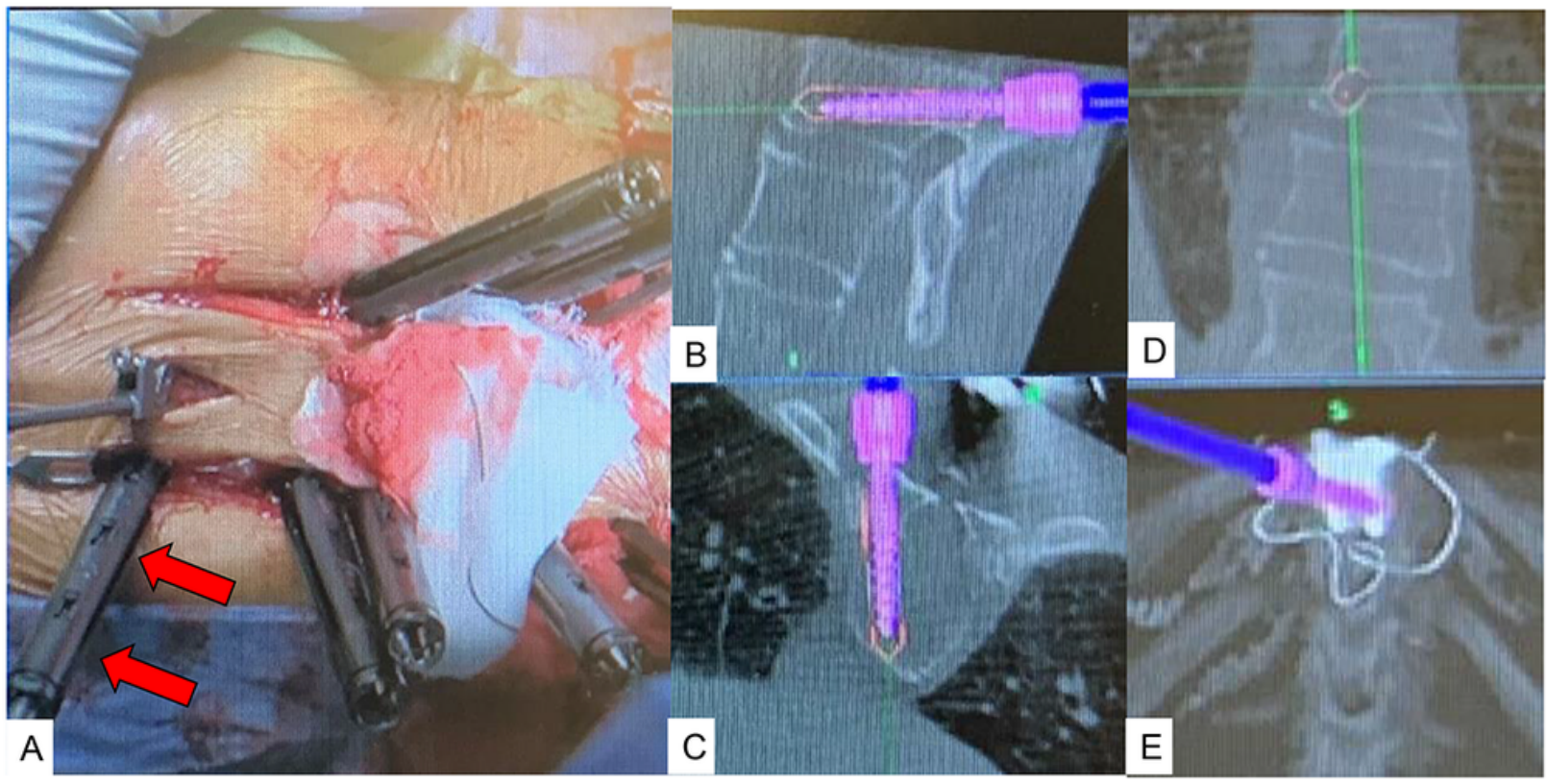


Figure 9

The lower angulation trajectory screw Screws of T11 and T12 makes the triangular fixation

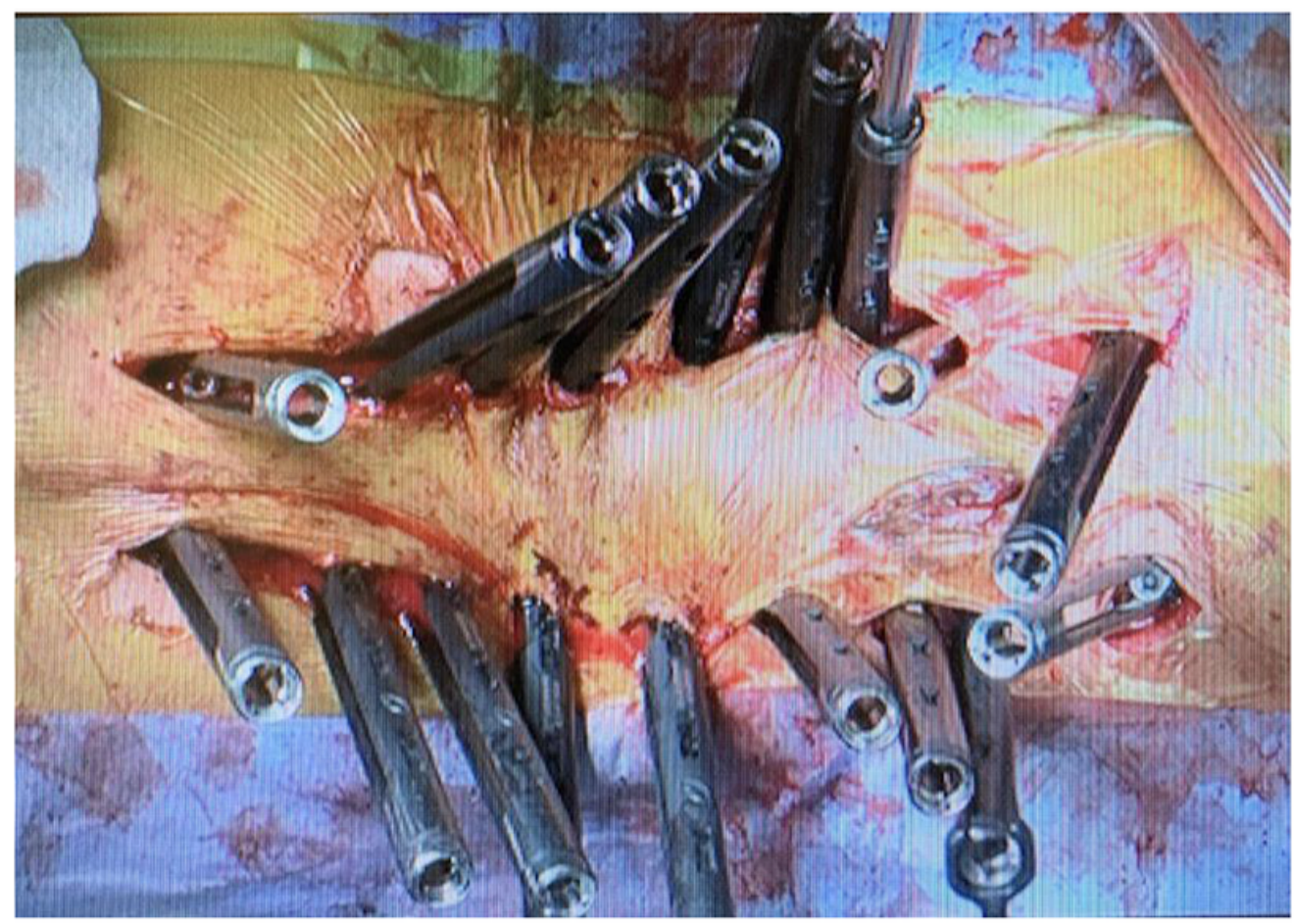

Figure 10

Figure 10

Percutaneous pedicle screw insertion All screws were inserted under navigation guidance 


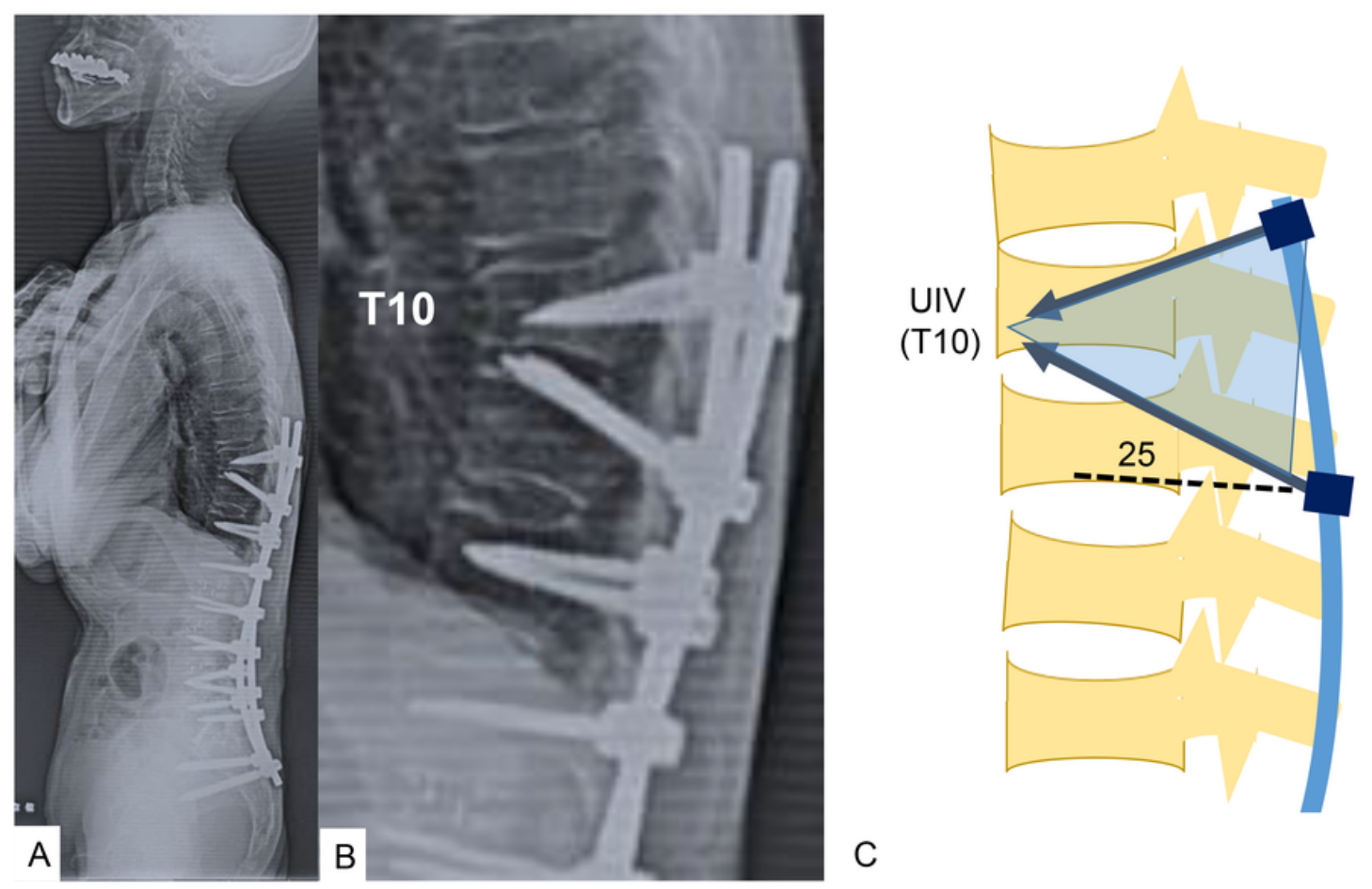

Figure 11

\section{Figure 11}

Triangular fixation T10 anatomical screw and T11 transdiscal screw make triangular fixation. 